\title{
Heat transfer characteristics and friction of turbulent swirling air flow through abrupt expansion
}

\author{
A. Khalii", A.E. Zohir ${ }^{* *}$ and A.M. Farid ${ }^{* *}$ \\ * Mechanical Power Eng. Dept., Faculty of Engineering, Tanta University, Tanta. \\ Mechanical Eng. Dept., Tabbin Institute for Metallurgical Studies, Cairo.
}

\begin{abstract}
Heat transfer and pressure drop characteristics of turbulent swirling air flow through a sudden expansion pipe with different swirl angles and different sudden expansion ratios were investigated experimentally. The effect of the sudden expansion ratio, Reynolds number, vane angle and swirl generator location on the heat transfer and pressure drop were examined. The test pipe is uniformly heated and the Reynolds number ranges from 9,000 to 41,000 . It was found that, inserting a swirl generator inside sudden expansion pipe causes an increase in both the relative mean Nusselt number and the enhancement efficiency of the tested pipe. The enhancement efficiency increases with Reynolds number decreasing while it increases with the increase in sudden expansion ratio (d/D decreases) and vane angle. A maximum efficiency up to $405 \%$ could be achieved. Correlations for Nusselt number and friction factor for the swirl flow are obtained. The performance evaluation criterion to access the real benefits in using the swirl generators of the enhanced tube is discussed.
\end{abstract}

Keywords: Sudden expansion, swirl flow, heat transfer, friction factor, enhancement efficiency.

\author{
Nomenclature \\ $C_{p} \quad$ Specific heat capacity of the fluid, J/kg.K \\ d Upstream pipe diameter, $\mathrm{m}$ \\ $D \quad$ Test section Pipe diameter, $\mathrm{m}$ \\ $f \quad$ Friction factor \\ $h \quad$ Heat transfer coefficient, $\mathrm{W} / \mathrm{m}^{2} . \mathrm{K}$ \\ $H \quad$ Step height, $H=0.5(D-d), \mathrm{m}$ \\ $K \quad$ Thermal conductivity of the fluid, W/m.K \\ $L \quad$ Test section pipe length, $\mathrm{m}$ \\ $\mathrm{m}$. Mass flow rate, $\mathrm{kg} / \mathrm{s}$ \\ $\mathrm{Nu}$ Nusselt number \\ $\Delta P$ Pressure drop, $\mathrm{Pa}$ \\ q. Heat flux, $\mathrm{W} / \mathrm{m}^{2}$ \\ $Q \quad$ Heat transfer rate, $\mathrm{W}$ \\ Re Reynolds number \\ $T$ Temperature, ${ }^{\circ} \mathrm{C}$ \\ $X$ Distance, $\mathrm{m}$
}

$\begin{array}{ll}U & \text { Flow velocity, } \mathrm{m} / \mathrm{s} \\ S & \text { Swirler position, } \mathrm{m} \\ \text { Greek Symbols } \\ \Theta \quad \text { Swirl generator vane angle, }{ }^{\circ} \\ \mu & \text { Viscosity of the fluid, N.s } / \mathrm{m}^{2} \\ \eta & \text { Efficiency } \\ \rho & \text { Density, } \mathrm{kg} / \mathrm{m}^{3} \\ \text { Subscripts } \\ m & \text { Mean } \\ x & \text { Local } \\ o & \text { Smooth pipe }(\mathrm{d} / \mathrm{D}=1) \text { without swirl } \\ i & \text { Inlet } \\ e & \text { Exit } \\ b & \text { Bulk } \\ r & \text { Relative } \\ s & \text { Surface } \\ h & \text { Heated }\end{array}$

transfer rate through pipes with no need to add any external power (passive techniques). The turbulent swirl flow through an abrupt axisymmetric expansion is a complex flow possessing several distinctly different flow regimes of recirculation and extremely high levels of turbulence. Heat transfer characteristics are often significantly altered by the nature of the flow separation and subsequent flow redevelopment. Swirl flow can be induced by different 
kinds of swirl generators such as injection, twisted tape, helical screw, vanes, etc.

The different parameters of swirling flow generated by injection were studied experimentally by Akpinar et al. [4, 5] and Çakmak and Yıldız [6]. They studied the effect of holes diameter, holes number and angle of injection on the heat transfer rate and pressure drop. They found that, using injector to create swirling flow enhances heat transfer rate but it increases the pressure drop and requires more pumping power.

Twisted tape was examined by many researchers as a swirl generator. Saha et al. [7, 8] studied the influence of length, twisted ratio, width, phase angle and rod diameter on heat transfer and pressure drop. Hong and Bergles [9] used twisted tape with different twisted ratio to reduce the size of the heat exchanger. Increasing in the heat transfer rate by up to $100 \%$ was found by Yildiz et al. [10] by using stripes twisted tape. An increase in the heat transfer coefficient between 1.28:2.4 was found by Chang et al. [11] by using broken twisted tape.

Gül and Evin [12] used short length helical screw to enhance the heat transfer inside pipe. They achieved a net energy gain up to $20 \%$ depending upon Reynolds number, tape angle and channels number. Many researches studied the swirling flow formed by inserting a propeller vane swirl generator inside pipe experimentally and numerically. Zaherzadeh and Jagadish [13] and Sarac and Bali [14] studied the influence of different propeller vane parameters (blade width, diameter, blades number, vane angle and swirl generator) on the heat transfer and pressure drop inside pipe. They found that Nusselt number and pressure drop increased with blades number increasing. Also Nusselt number and pressure drop increased with vane angle decreasing. A continuous swirling flow induced by more than one propeller vane inserted inside pipe at equal interval distance was studied by [15 - 19]. They examined the effect of different parameters like (vane angle,

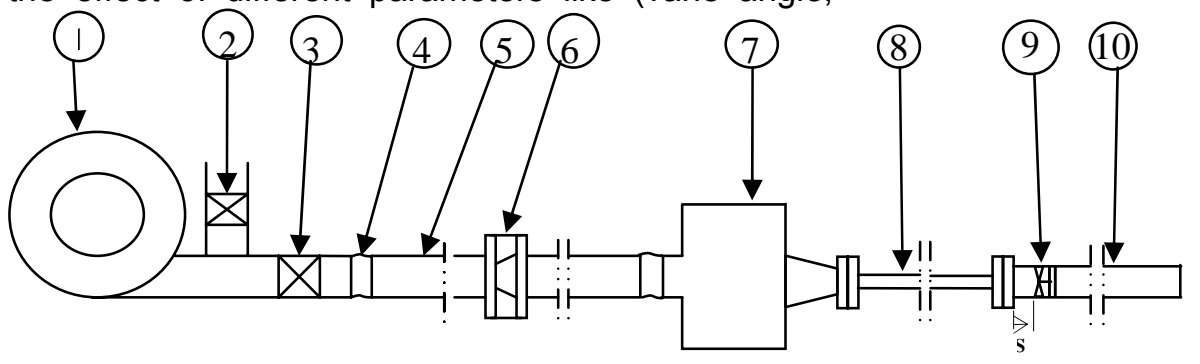

Fig 1 Test rig layout. number of swirl generator, blades number...etc) on the heat transfer rate and pressure drop. They found that; using more than one propeller vane gave results better than using a full length twisted strips. They also found that Nusselt number and efficiency increased with vane angle decreasing, except for Eiamsa-ard et al. [19] who found that the efficiency and the heat transfer increased with vane angle increase. Numerical studies for turbulent swirling flow characteristic through sudden pipe expansion were done by Vanierschot and Bulck [20], who found that the reattachment length for swirling flow through sudden expansion depends on the swirl number, expansion ratio and the reattachment length at zero swirls. Dellenback et al. [21] and [22] studied the effect of swirling motion created by injectors inside sudden pipe expansion on the velocity and heat transfer. They found that as swirl number increased from zero to 1.2, the peak local Nusselt number increased from 3 to 9.5 times larger than fully developed value and its location moved towards the inlet.

The present work investigates the heat transfer, pressure drop and efficiency enhancement for swirling flow through sudden pipe expansion. Propeller swirl generator with vane angles $\left(15^{\circ}, 30^{\circ}\right.$, $45^{\circ}$ and $60^{\circ}$ ) is inserted at distance $S=H, 3 H, 5 H$, $10 \mathrm{H}, 20 \mathrm{H}$ and $40 \mathrm{H}$ from the test pipe entrance to investigate its influence on heat transfer inside sudden pipe expansion (sudden expansion ratio; $\mathrm{d} / \mathrm{D}=0.32,0.46$ and 0.61 ). Air with flow Reynolds number ranged from 9000 to 41000 was used as the working fluid.

Test Rig: The test rig consists of a $7.0 \mathrm{HP}$ blower that blows atmospheric air into the test tube through the control unit, as shown in figure 1. The control unit consists of control valve and by-bass valve, and then the air passes through the orifice meter. The air is then passed through the settling chamber, which is used to

1. Air blower

2. By-pass valve

3. Flow control valve

4. Flexible connection

5. Upstream tube of orifice

6. Orifice meter

7. Settling chamber

8. Upstream calming tube

9. swirl generator

10. Test section 
Am. J. Sci. Ind. Res., 2010, 1(2): 364-374

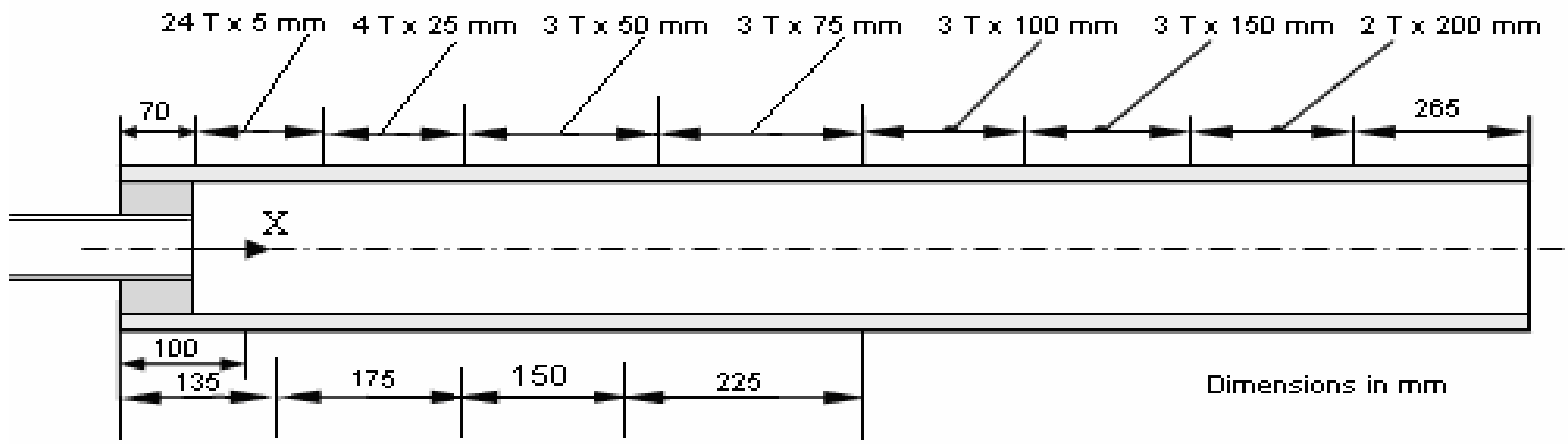

Fig 2 Thermocouple distribution on the downstream test pipe.

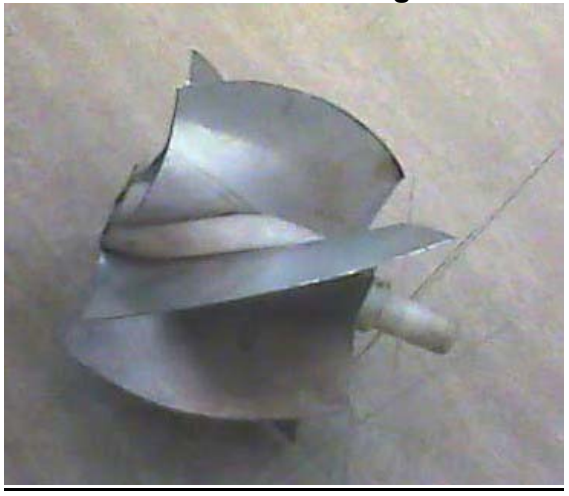

Fig 3a Photograph of a swirl generator.

damp the flow instability, and deliver air to the test section. The test section consists of upstream and downstream pipes. The upstream pipe is a PVC tube with diameters of $d=25,37.5$ and $50 \mathrm{~mm}$ and lengths $=20 d: 25 d$ to have a fully developed flow. The downstream pipe consists of a main pipe made of stainless steel with diameter $D=82 \mathrm{~mm}, 2000 \mathrm{~mm}$ length and $2 \mathrm{~mm}$ thickness. The main pipe is heated by eleven heaters wound around the tube with $1 \mathrm{~mm}$ pitch to achieve a uniform heat flux. Sheets of aluminum of $0.2 \mathrm{~mm}$ thickness were wound above and under the heaters to distribute the heat uniformly. Then a layer of glass wool insulation $(50 \mathrm{~mm}$ thickness) was employed to cover the pipe to minimize the heat loss to the atmosphere. The surface temperatures were measured by 49 thermocouple of $\mathrm{K}$ type. The thermocouples were located at different axial positions with spacing ranged from $5 \mathrm{~mm}$ near the sudden expansion corner to $200 \mathrm{~mm}$ near the exit as shown in figure 2. The swirling flow is induced by propeller vane as shown in figure 3 . The core of the propeller vane is made of Artelon and has $15 \mathrm{~mm}$ diameter and $50 \mathrm{~mm}$ length. The blades are made of aluminum $0.4 \mathrm{~mm}$ thickness. The propeller vane has $80 \mathrm{~mm}$ outer diameter and 5 blades fixed at $\theta=15^{\circ}, 30^{\circ}, 45^{\circ}$ or $60^{\circ}$. The propeller

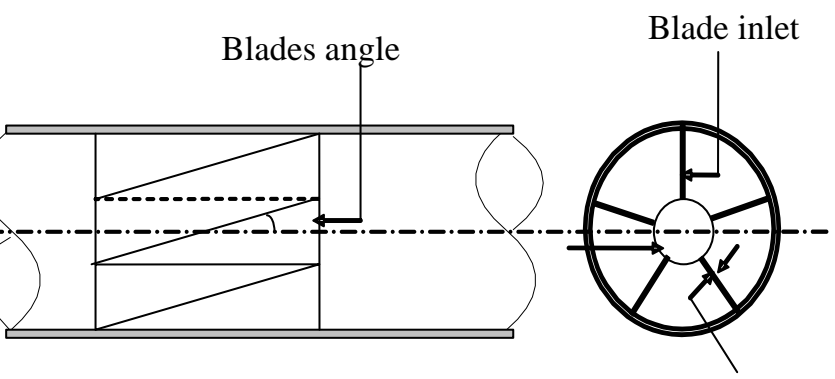

Blades thickness

Fig $3 b$ Details of swirl generator.

vane is installed at distance from the sudden expansion corner $S=H, 3 H, 5 H, 10 H, 20 H$ or $40 H$. The swirl generators with vane angle $\theta=15^{\circ}, 30^{\circ}$, $45^{\circ}$ and $60^{\circ}$ are referred to be as swirler 1, 2, 3 and 4 ; respectively.

Analysis: The net heat transfer by convection to air can be calculated from Eq. (1). The local mean bulk temperature of air in each segment of the test section is calculated from Eq. (2). The properties of air are determined at mean bulk temperature. The heat lost $Q_{\text {loss }}$ has been measured using Fourier's low of radial heat conduction by measuring the outer surface temperatures of the insulation at the corresponding points where the tube wall surface temperature were measured. The heat loss was found to vary between $5 \%$ and $6 \%$ of the heater input power. In the analysis $Q_{\text {loss }}$ was assumed to be $6 \%$.

$$
\begin{aligned}
& Q_{n e t}=\left(Q-Q_{\text {loss }}\right)=n \& k C_{p}\left(T_{b e}-T_{b i}\right) \\
& T_{b x}=T_{b i}+q_{o} \pi D L_{x} / n \& C_{p}
\end{aligned}
$$

where $\&_{0}$ is the uniform heat flux and can be calculated from 


$$
\&=\text { const. }=Q_{\text {net }} / \pi D L_{h}
$$

The local and mean heat transfer coefficients are determined from Eqs. (4) and (5). The local and mean Nusselt number can be calculated, respectively, from Eq. (6).

$$
\begin{aligned}
& h_{x}=\oiint_{0} /\left(T_{s x}-T_{b x}\right) \\
& h_{m}=\frac{1}{L} \int_{0}^{L_{h}} h_{x} d L_{x} \\
& N u_{x}=h_{x} D / k, \\
& N u_{m}=h_{m} D / k
\end{aligned}
$$

The friction factor can be calculated from Darcy equation (7).

$$
\Lambda P=f \frac{L}{D} \frac{\rho u^{2}}{2}
$$

where $\Delta P$ is the pressure drop across the test pipe which measured between two points; before the sudden expansion and at the end of the test section. Due to the enlargement in the diameter of the pipe, $\Delta P$ may have a negative or positive value according to the investigated independent parameters.

The enhancement efficiency $\eta$ is defined as the ratio of the heat transfer coefficient for the inserted tube $h_{m}$ to that for plain tube $h_{o}$ at same pumping power and it may be more than unity according to ref [19].

$$
\eta=\left[h_{m} / h_{o}\right]
$$

An error analysis is carried out for the relevant parameters and the average uncertainties are found to be: $\pm 1.09 \%$ for mean velocity, $\pm 1.09 \%$ for Reynolds number, $\pm 4.8 \%$ for Nusselt number, $\pm 1.05 \%$ for friction factor and $\pm 4.9 \%$ for the enhancement efficiency.

\section{RESULTS AND DISCUSSION}

The experimental investigations for swirling flow induced by propeller vane swirl generator with vane angle $\left(\theta=15^{\circ}, 30^{\circ}, 45^{\circ}\right.$ and $\left.60^{\circ}\right)$ located at position $S=H, 3 H, 5 H, 10 H, 20 H$ and $40 H$ through sudden expansion pipe, of uniform heat flux, with expansion ratios of $(d / D=0.32,0.46$ and 0.61$)$ are described in this section. The inlet air temperatures were varied between $25-40^{\circ} \mathrm{C}$ while the exit air temperatures were varied between $40-60^{\circ} \mathrm{C}$. Firstly, the experiments were done for heat transfer inside smooth pipe $(d / D=1)$ without swirl. The results were compared with Dittus-Boelter [23] correlation to check the validity of the experimental data and a good agreement between the experimental results and Dittus-Boelter equation was achieved with deviation $\pm 6 \%$.
Influence of Sudden Expansion on local Nusselt number: The influence of sudden expansion ratio on the relative local Nusselt number at different Reynolds numbers is shown in Figure 4. The relative local Nusselt number is the value of local Nusselt number normalized by the corresponding local Nusselt number for constant area pipe $(d / D=1)$. Figure 4 shows that, at the same Reynolds number, as the sudden expansion ratio increases ( $d / D$ decreases) the Nusselt number increases and the position of the maximum Nusselt number moves slightly away from the inlet. A maximum enhancement in relative local Nusselt number by up to 4.8 times is obtained with $d / D=0.32$ and $R e=$ 15,000 at position $X / H=12$. The effect of inserting swirl generator inside sudden pipe expansion on the relative local Nusselt number is shown in Figures 58. Figures show that inserting swirl generator inside sudden expansion pipe increases the local heat transfer coefficient. In addition, the figures show that the local Nusselt number for swirling flow through sudden pipe expansion has similar trend as that of the sudden expansion only. But when the swirl generator was inserted inside pipe the length of the recirculation zone decreases and the peak local Nusselt number moves towards the inlet. As seen from Figure 7; the peak relative local Nusselt number increases with increasing vane angle and moves towards the inlet. Also at small vane angle; the peak relative local Nusselt number increases with the distance $S$ increasing (distance between the location of the swirl generator and the sudden expansion) and move away from the entrance. At high vane angle; the peak relative local Nusselt number increases with decreasing the distance $S$ and moves towards the inlet.

Influence of Reynolds Number: The effect of Reynolds number on the heat transfer is shown in Figures 9 and 10. The figures show relative mean Nusselt number $N u_{m r}\left(N u_{m}\right.$ of sudden expansion with swirl flow is normalized by $N u_{m o}$ for smooth pipe $(d / D$ $=1$ ) without swirl) versus $R e$ at different $d / D$ values and different vane angles. Figures show that for all Reynolds numbers, the value of $N u_{m r}$ are above unity which mean that, inserting of swirl generator through sudden expansion pipe increases the heat transfer rate. As shown in figures 9 and $10, N u_{m r}$ increases or decreases with decreasing $R e$ number depending on $d / D$ ratio with swirl flow. This effect is due to the increase in $N u_{m}$ for smooth pipe $(d / D=1)$ with $R e$ number increasing is higher than that for swirling flow 
through sudden expansion pipe. In the whole studied range for the varied parameters, $N u_{\operatorname{mrmax}}=3.58$ at $R e$ $=1000$ and $N u_{\operatorname{mrmax}}=2.74$ at $R e=40,000$. The

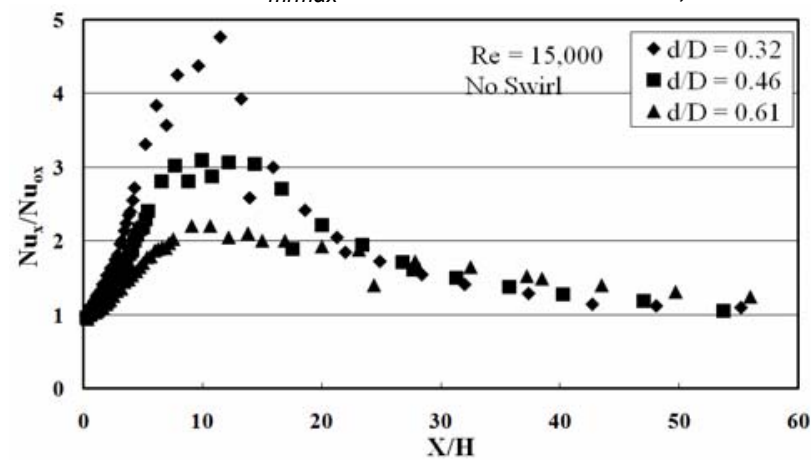

Fig 4 Variation of $N u_{x} / N u_{0 x} v s . X / H$ with $d / D$

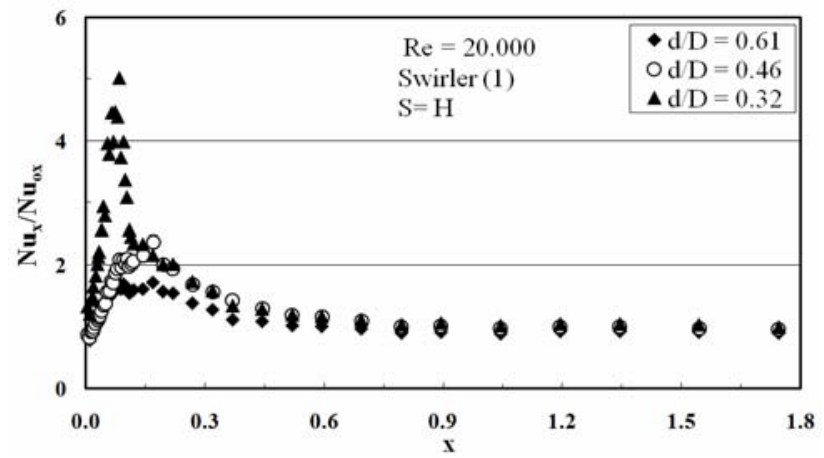

Fig 6 Variation of $N u_{x} / N u_{0_{x}}$ vs. $X$ with $d / D$.

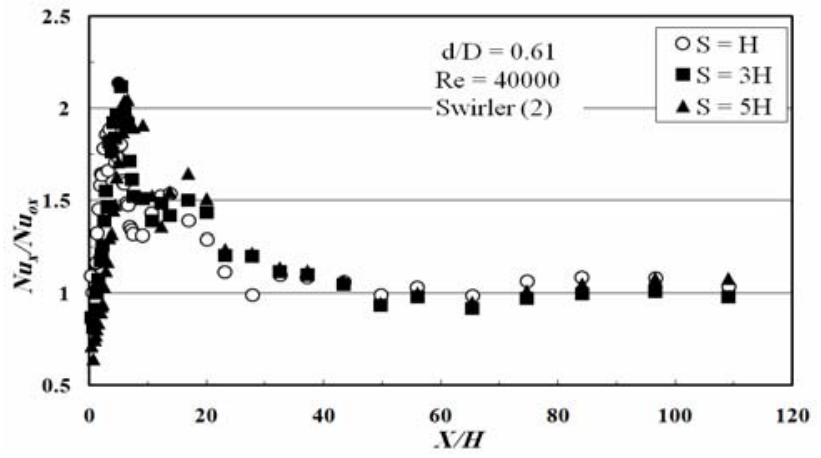

Fig 8 Effect of swirler position on $\mathrm{Nu}_{x} / \mathrm{Nu} u_{0 x}$. influence of $R e$ number on the friction factor is shown in figures 11 and 12. The friction factor decreases with increasing Reynolds number.

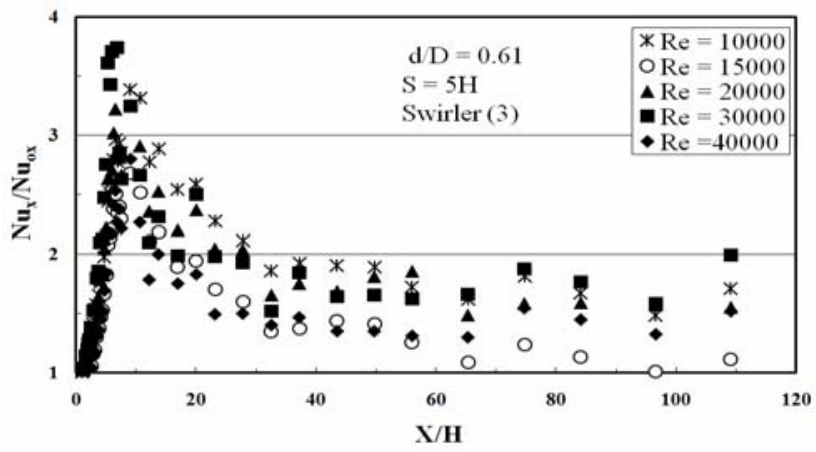

Fig 5 Variation of $N u_{x} / N_{0_{x}}$ vs. $X / H$ with $R e$.

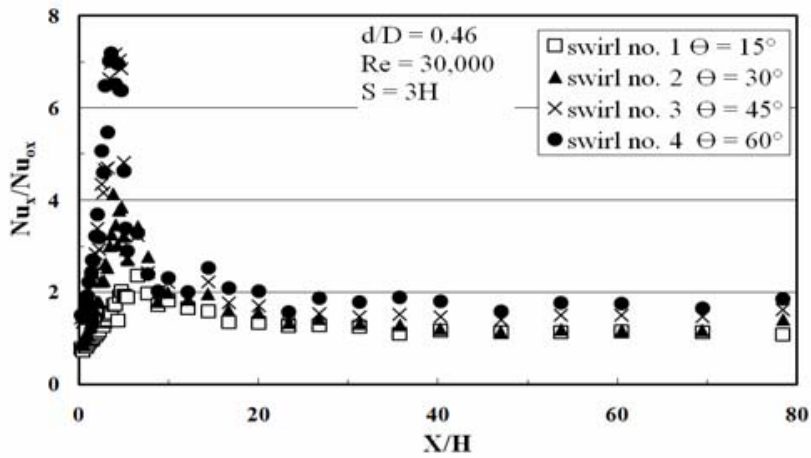

Fig 7 Effect of vane angle on $N u_{x} / N u_{0_{x}}$ with $\mathrm{X} / \mathrm{H}$.

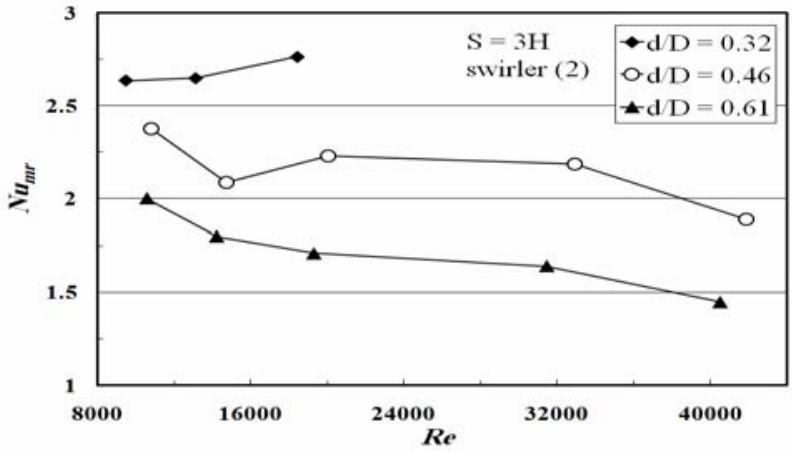

Fig 9 Variation of $\mathbf{N u} u_{m r}$ with $R e$. and d/D 


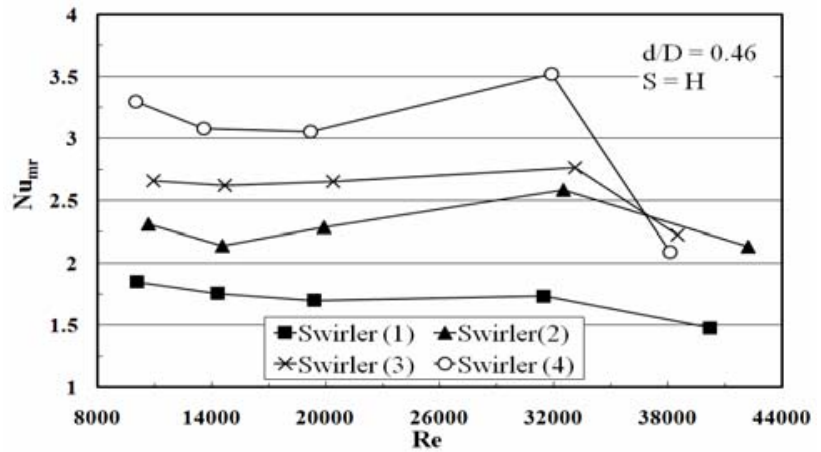

Fig 10 Variation of $\mathrm{Nu}_{m r}$ with Re. for different swirlers

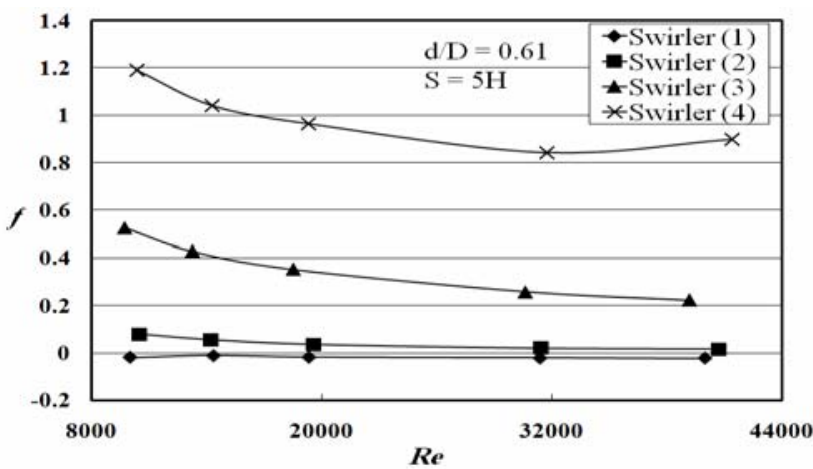

Fig 12 Effect of $\boldsymbol{R e}$ on $\boldsymbol{f}$ for different swirlers

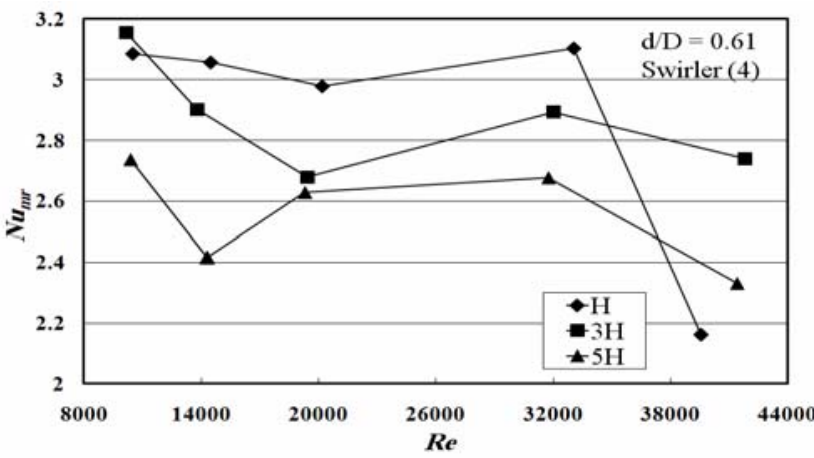

Fig 14 Effect of swirler position on $N u_{m r}$ for $d / D=0.61$

Influence of Sudden Expansion Ratio: The effect of sudden expansion ratio on the heat transfer rate is presented in figure 9. The $N u_{m r}$ increases with decreasing $d / D$ because at the same $R e$ number as $d / D$ decreases the axial flow velocity at the downstream pipe increases. Increasing of the axial velocity causes the swirl generator to rotate at high speed and increases the swirling flow intensity and turbulence generation. Also the length of the recirculation zone increases with decreasing $d / D$. For these reasons the heat transfer rate increases with decreasing $d / D$. While as the vane angle increases the reattachment point moves towards the inlet and

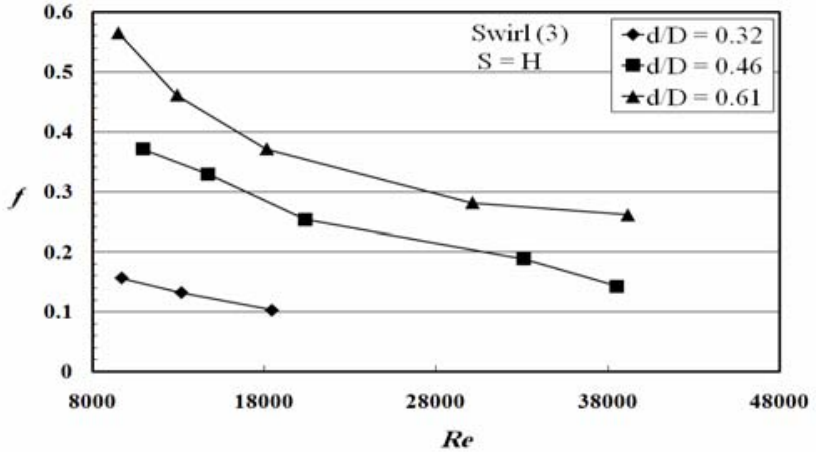

Fig 11 Relation between $f$ and $R e$ for different ratio of $d / D$.

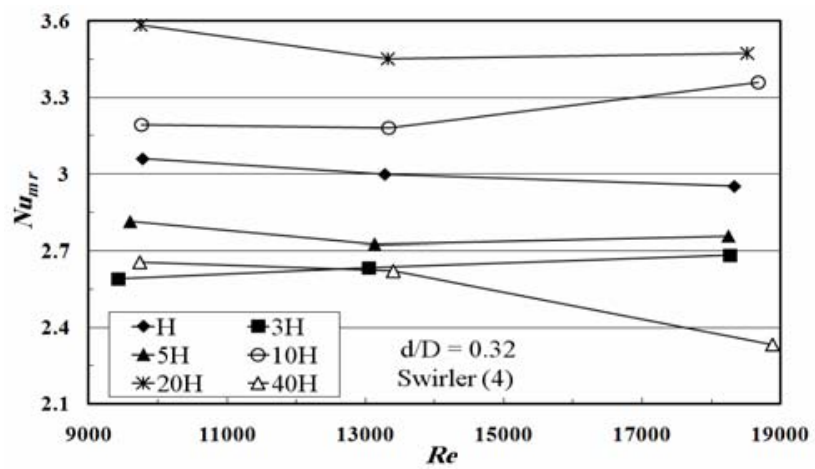

Fig 13 Effect of swirler position on $N u_{m r}$ for $d / D=0.32$

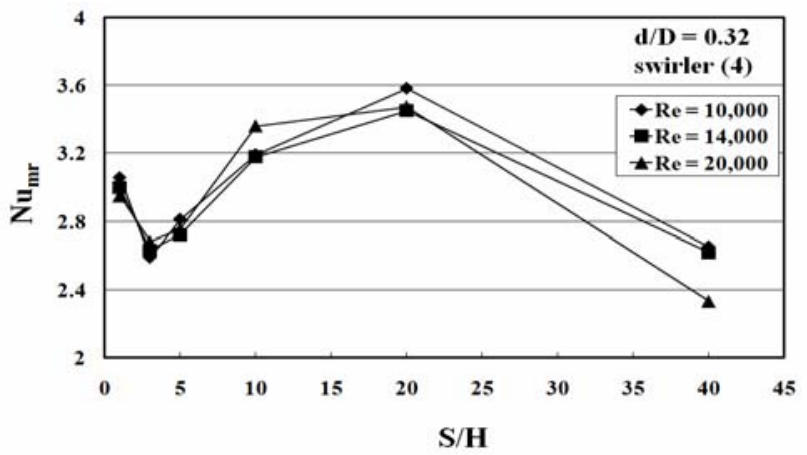

Fig 15 Effect of swirler position on $N u_{m r}$ for $d / D=0.32$

the length of the recirculation zone decreases. Therefore the effect of $d / D$ on heat transfer becomes low with increasing vane angle. In the whole studied range for the varied parameters, $N u_{\operatorname{mrmax}}=3.58$ at $d / D=0.32$ while $N u_{\operatorname{mrmax}}=3.1$ at $d / D=0.61$. Figure 11 presents the effect of $d / D$ ratio on friction factor, $f$. The figures show that as $d / D$ decreases, $f$ decreases because the area of the recirculation zone increases with decreasing $d / D$. The boundary layer is destroyed by the back flow encountered in the recirculation zone resulting in a decrease in the friction between the fluid and the tube wall. 
Effect of Swirl Vane Angle: The influence of vane angle of swirl generator blades on heat transfer is presented in Figure 10. As shown in this figure, the $N u_{m r}$ increases with increasing vane angle. This improvement in $N u_{m r}$ occurs due to the increasing in blade angle that leads to decreasing of the reattachment length. The decrease of the recirculation zone causes shear rates and hence increases the turbulence kinetic energy causing higher heat transfer rates, [24]. This enhancement is also promoted by increasing the tangential velocity component at nominally constant values of axial velocity. The effect of vane angles on heat transfer is higher at the high values of $d / D$ as discussed earlier. This is due to the interference between the effect of decreasing $d / D$ and increasing vane angle on the length of the recirculation region. The effect of increasing of vane angle is higher at high $d / D$ and lower with $d / D$ decreasing. In the whole studied range for the varied parameters, $N u_{\operatorname{mrmax}} 3.58$ at $\theta=60^{\circ}$ while $N u_{\operatorname{mrmax}}=2.81$ at $\theta=15^{\circ}$. The effect of the vane angle on $f$ is presented in figure 12. The figure shows that, $f$ increases with increasing $\Theta$. This effect is due

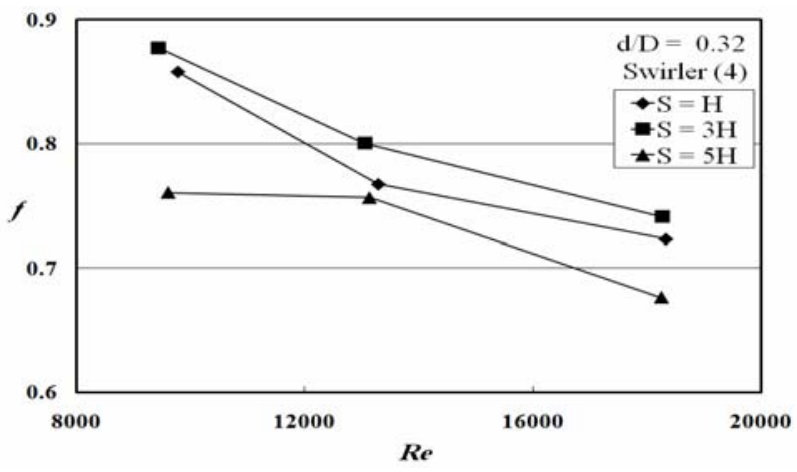

Fig 16 Effect of $R e$ on $f$ for $d / D=0.32$.

Effect of Swirl Flow Only: The results of $\mathrm{Nu}_{\mathrm{r}}$ (where $\mathrm{Nu}_{\mathrm{r}}$ is the ratio between $N u_{m}$ for swirling flow through sudden expansion and $N u_{m}$ for sudden expansion without swirl) show that the relative mean values are above unity which means that insertion of swirl flow through sudden expansion pipe enhances the heat transfer rate. Also the results show slightly increase in the $N u_{r}$ with decreasing of Reynolds number. The $N u_{r}$ increases also with increasing of $d / D$ and swirler vane angle. For the studied parameters range, $N u_{\text {rmax }}$ $=2.08$ at $R e=14,000, d / D=0.61, \theta=60^{\circ}$ and $S=H$.

Heat Transfer Enhancement Efficiency: The present results showed that using of propeller swirl generator increases both the heat transfer rate and to the increase in the tangential velocity which increases the flow paths length and increases the contact between the fluid and tube surface which causes an increase in the friction factor.

Effect of Swirl Generator Position: Both enhancement and reduction can be observed with increasing the distance $S$ (distance between test tube entrance and the swirl generator). At small vane angles, $N u_{m r}$ increases with increasing $S$. At high vane angle, as $S$ increases, $N u_{m r}$ decreases to a minimum value at $S=5 \mathrm{H}$. Then, $N u_{m r}$ increases, with the distance $S$ increasing, to a peak value at $S=$ $20 \mathrm{H}$. After that with the distance $S$ increasing, $N u_{m r}$ decreases as shown in figures 13-15. The results shows that $N u_{\operatorname{mrmax}}=2.66$ at $\mathrm{S}=40 \mathrm{H}$ and $N u_{\operatorname{mrmax}}=$ 3.58 at $S=20 H$ while $N u_{\operatorname{mrmax}}=3.52$ at $S=H$. Swirl generator position also has a significant effect on friction factor $f$ as shown in figures 16 and 17. These figures show that, as the swirl generator moves away from the entrance, the friction factor decreases or increases depending on the sudden expansion ratio and the swirl generator vane angle.

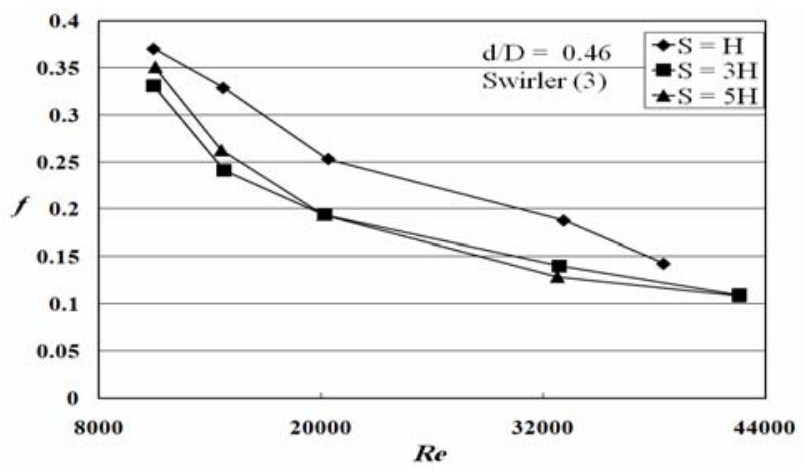

Fig 17 Effect of $R e$ on $f$ for $d / D=0.46$.

pressure drop. The enhancement efficiency is used to show whether, in terms of energy saving, inserting a swirl generator through pipe sudden expansion is effective or not for heat transfer rate. Enhancement efficiency is the heat transfer coefficients for swirling flow through sudden pipe expansion normalized by the corresponding fully developed heat transfer coefficient for the sudden expansion without swirl at constant pumping power.

Figures 18-22 show the effect of swirling flow through sudden expansion of a pipe on the enhancement efficiency. The figures show that the enhancement efficiency is generally greater than unity. This means that using of a propeller swirl 
generator after a sudden expansion of a pipe increases the efficiency. The figures also show that the enhancement efficiency decreased with increasing the Reynolds number because as Reynolds numbers increases, the heat transfer coefficient for the swirling flow through sudden pipe expansion increases. This effect is due to the high swirl intensity which imposed on the flow and to the decrease of the thermal boundary layer as a result of increasing the radial turbulent fluctuations. The increasing in heat transfer coefficient, for the plain pipe, is higher than that for swirling flow in sudden expansion. While both the heat transfer coefficient for swirling flow through sudden pipe expansion and plain pipe increase with $R e$ but the ratio of both coefficients may decrease. Therefore, the swirling is more effective for heat transfer at low Reynolds numbers.

The effect of $d / D$ values on the efficiency is shown in Figures 18 and 19. As shown in figures, the maximum efficiency is obtained at the low value of $d / D=0.32$. This means that the enhancement efficiency increases with decreasing $d / D$. This is because decreasing of $d / D$, the heat transfer coefficient increases. Also the pressure drop decreases with decreasing of $d / D$ due to the increase of the recirculation zones and the decrease of the boundary layer thickness. So, the efficiency increases with sudden expansion ratio increasing.

$$
\begin{aligned}
& N u_{m r}=-1.87 \times 10^{-10} \mathrm{Re}^{2}-1.81(d / D)^{1.5}+0.11(\tan \theta)^{3}-3.39 \times 10^{-2} /(\tan \theta)^{2}+14.21 S^{2.5}+S^{3}+1.95 \\
& f=-2.04 \times 10^{-8} \mathrm{Re}^{1.5}-\frac{0.132}{(d / D)}+3 \times 10^{-4}(\tan \theta)^{2}-0.406 S+0.146 \\
& \eta=-4.8 \times 10^{-10} \mathrm{Re}^{2}-1.96(d / D)^{1.5}+7.85 \times 10^{-2}(\tan \theta)^{3}-\frac{3.51 \times 10^{-2}}{(\tan \theta)^{2}}+20.878 S^{2.5}+S^{3}+3.312
\end{aligned}
$$

The correlations are valid for $d / D=0.32$ to $0.61, \theta=$ $15^{\circ}$ to $60^{\circ}, S=H$ to $5 H(\mathrm{~m})$ and $R e=9000$ to 41000 within r.m.s error about $16.6 \%, 7.7 \%$ and $17.7 \%$ for $\mathrm{Nu}_{m r}, f$ and $\eta$; respectively. Figures 23-25 show comparison between the experimental results and the correlations, and a reasonable agreement was found as shown in these figures. 
Am. J. Sci. Ind. Res., 2010, 1(2): 364-374

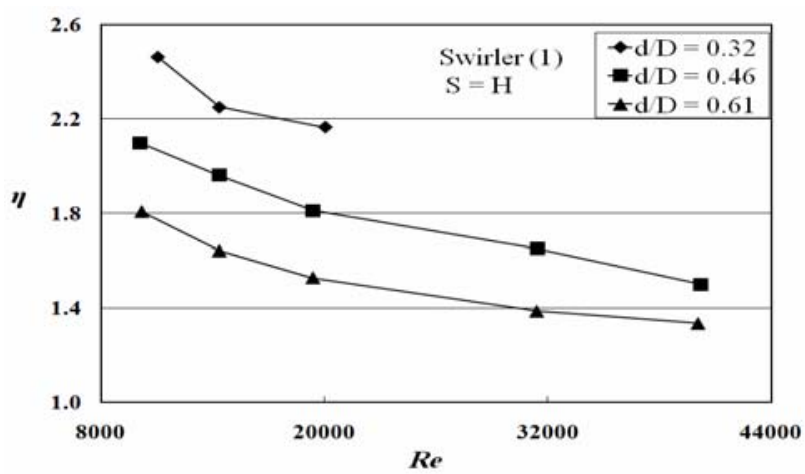

Fig 18 Effect of $\operatorname{Re}$ on $\eta$ for swirler (1).

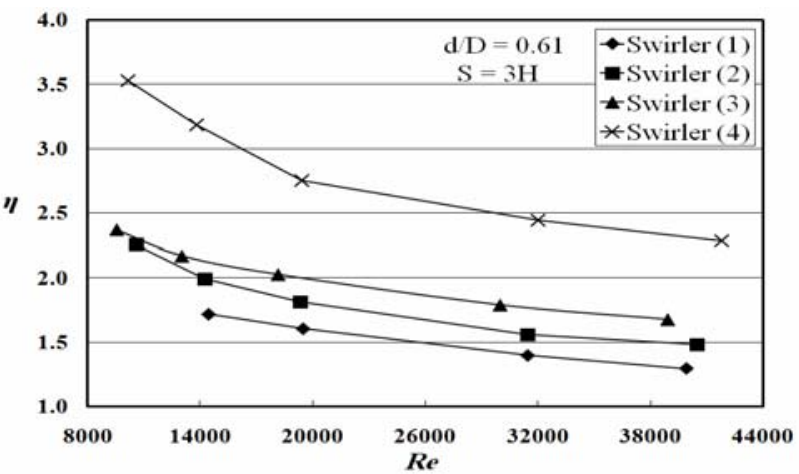

Fig 20 Effect of Re on $\eta$ for $d / D=0.61$.

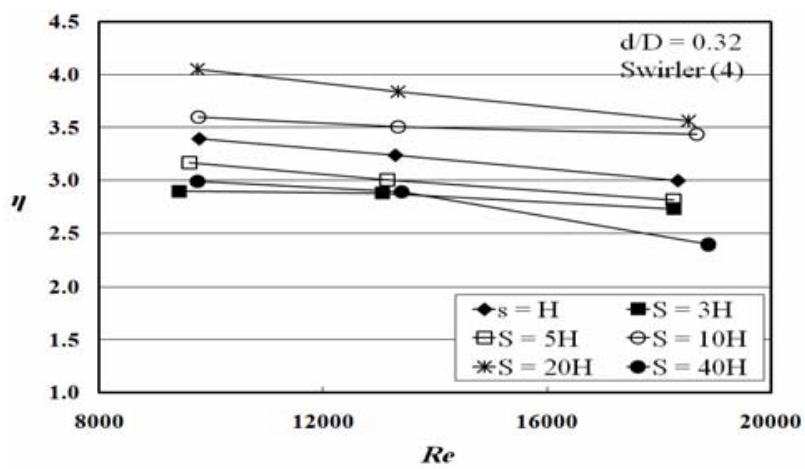

Fig 22 Effect of $R e$ on $\eta$ with position for swirler (4).

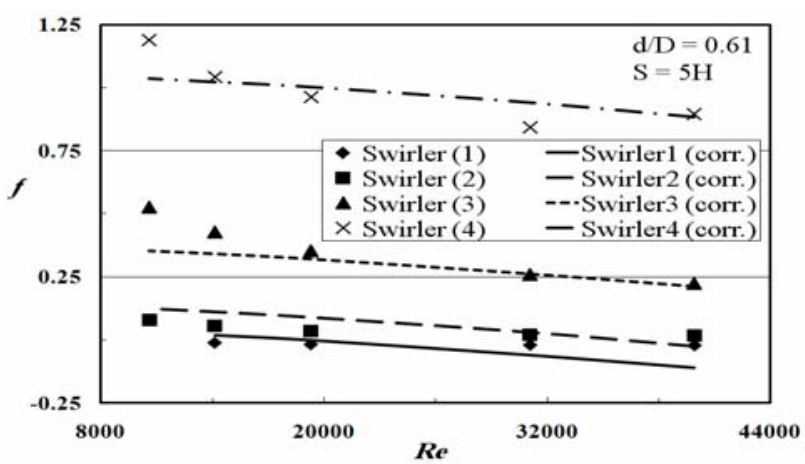

Fig 24 Correlation of results of $f$ for $d / D=0.61$.

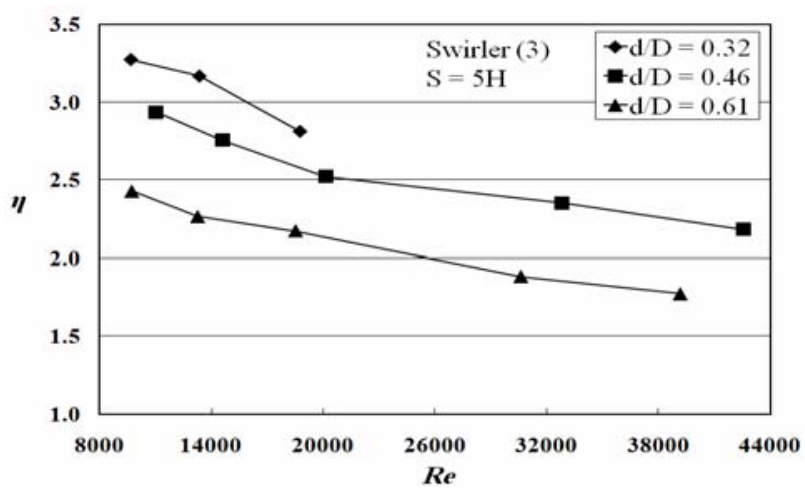

Fig 19 Effect of $\operatorname{Re} \eta$ for swirler (3).

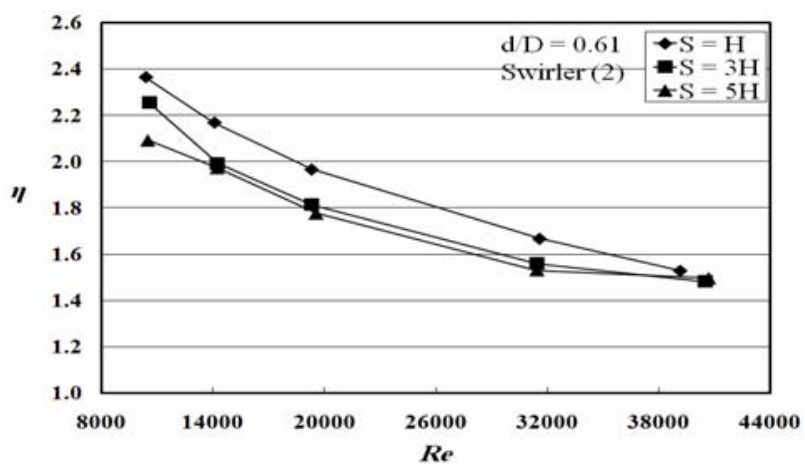

Fig 21 Effect of Re on $\eta$ with position for swirler (2).

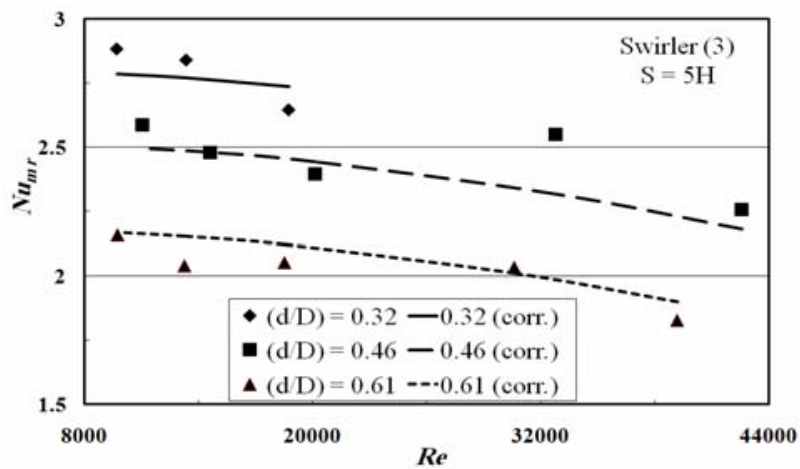

Fig 23 Correlation of results of $\mathbf{N u}$ mr for swirler (3).

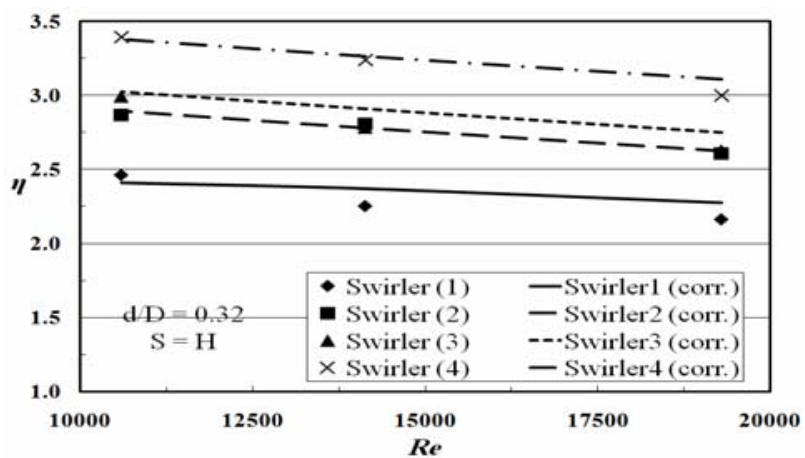

Fig 25 Correlation of results of $\eta$ for $\mathrm{d} / \mathrm{D}=\mathbf{0 . 3 2}$. 


\section{CONCLUSION:}

The present work is an experimental investigation of heat transfer and pressure drop characteristics of turbulent swirling air flow through an axisymmetric sudden expansion pipe. The examined Reynolds number, $\operatorname{Re}=9,000$ to $40,000, d / D=0.32,0.46$ and 0.61 , swirler vane angle $\theta=$ $15^{\circ}, 30^{\circ}, 45^{\circ}$ and $60^{\circ}$ and swirler position $\mathrm{S}=\mathrm{H}, 3 \mathrm{H}, 5 \mathrm{H}$, $10 \mathrm{H}, 20 \mathrm{H}$ and $40 \mathrm{H}$. Based on the present study, the following conclusions are surmised:

1. As Reynolds number increases the peak local Nusselt number increases and move towards the inlet, a maximum enhancement in relative local Nusselt number was up to 4.8 times obtained with $d / D=0.32$ and $R e=15,000$ at position $X / H=12$. The mean Nusselt number increases with Reynolds number increasing for flow with and without swirl, while Relative mean Nusselt number decreases with increasing Reynolds number, $N u_{\operatorname{mrmax}}=3.58$ at $R e=1000$ and $N u_{\text {mrmax }}=2.74$ at $R e=40,000$.

2. As the sudden expansion ratio increases, the relative mean Nusselt number increases while the friction factor decreases, $N u_{\operatorname{mrmax}}=3.58$ at $d / D=0.32$ while $N u_{\operatorname{mrmax}}=$ 3.1 at $d / D=0.61$.

3. Both the relative mean Nusselt number and friction factor $(f)$ increase with increasing vane angle $(\theta)$, $N u_{\operatorname{mrmax}} 3.58$ at $\theta=60^{\circ}$ while $N u_{\operatorname{mrmax}}=2.81$ at $\theta=15^{\circ}$.

4. If the swirl generator is located near the pipe inlet (separation zone), a reduction in the heat transfer rate is observed. Moving the swirl generator away from the sudden expansion point causes a significant decrease in the relative mean Nusselt number and then it increase to a peak value at a position of about $20 \mathrm{H}$, and after that, it decreases, $N u_{\operatorname{mrmax}}=2.66$ at $\mathrm{S}=40 \mathrm{H}$ and $N u_{\text {mrmax }}=3.58$ at $S=20 H$ while $N u_{\operatorname{mrmax}}=3.52$ at $\mathrm{S}=$ $\mathrm{H}$.

5. Although the Nusselt number increases with the Reynolds number, the enhancement efficiency decreases by increasing the Reynolds number. The efficiency also increases with the increase of the sudden expansion ratio and the vane angle, the highest enhancement efficiency of $405 \%$ was obtained at $S=20 H$ and $R e=9746$.

6. Empirical correlations are developed for Nusselt number, friction factor and enhancement efficiency. The predicted values are in reasonable agreement with the experimental results, The correlations are valid for $d / D$ $=0.32$ to $0.61, \theta=15^{\circ}$ to $60^{\circ}, S=H$ to $5 H(\mathrm{~m})$ and $R e$ $=9000$ to 41000 within r.m.s error about $16.6 \%, 7.7 \%$ and $17.7 \%$ for $N u_{m r}, f$ and $\eta$; respectively.

\section{REFERENCES}

1. Zimparov, V., "Energy conservation through heat transfer enhancement techniques", Int. J. Energy Res. 26 (2002) 675-696.
2. Bilen, K., K. Bakirci, S. Yapici and T. Yavuz"Heat transfer from a plate impinging swirl jet", Int. J. Energy Res. 26 (2002) 305-320.

3. Datta, A., "Influence of inlet flow conditions on the performance of a swirl-stabilized combustor burning liquid fuel spray", Int. J. Energy Res. 24 (2000) 373390.

4. Akpinar, E.K., Y. Bicer, C. Yildiz and D. Pehlivan, "Heat Transfer Enhancements in A Concentric Double Pipe Exchanger Equipped With Swirl Elements", Int. Commun. Heat Mass Transfer, 31 (6) (2004) 857-868.

5. Akpinar, E.K. and Y. Bicer, "Investigation of Heat Transfer and Exergy Loss in A Concentric Double Pipe Exchanger Equipped With Swirl Generator", Int. J. of Thermal Sciences 44 (2005) 598-607.

6. Çakmak, G. and C. Yıldız, "The Influence of the Injectors with Swirling Flow Generating on the Heat Transfer in the Concentric Heat Exchanger", Int. Commun. in Heat and Mass Transfer 34 (2007) 728739.

7. Saha, S.K. and A. Dutta, "Thermohydraulic Study of Laminar Swirl Flow through a Circular Tube Fitted with Twisted Tapes", J. Heat Transfer 123 (3) (2001) 417427.

8. Saha, S.K., A. Dutta and S.K. Dhal, "Friction and Heat Transfer Characteristics of Laminar Swirl Flow through a Circular Tube Fitted with Regularly Spaced Twisted Tape Elements", Int. J. Heat and Mass Transfer 44 (2001) 4211-4223.

9. Hong, S.W. and A.E. Bergles, "Augmentation of Laminar Flow Heat Transfer in Tubes by Means of Twisted-Tape Inserts", ASME J. Heat Transfer 98, (1976) 251-256.

10. Yildiz, C., Y. Bicer and D. Pehlivan, "Effect of Twisted Strips on Heat Transfer and Pressure Drop in Heat Exchangers", Energy Convers. Management 39 (3/4) (1998) 331-336.

11. Chang , S. W., T. L. Yang and J. S. Liou, "Heat Transfer and Pressure Drop in Tube with Broken Twisted Tape Insert', Experimental Thermal and Fluid Science 32 (2007) 489-501.

12. Gül, H. and D. Evin, "Heat Transfer Enhancement in Circular Tubes Using Helical Swirl Generator Insert at The Entrance", Int. J. of Thermal Sciences 46 (2007) 1297-1303.

13. Zaherzadeh, N.H. and B.S. Jagadisht, "Heat Transfer in Decaying Swirl Flows", Int. J. Heat and Mass Transfer. Vol. 18, (1975) 941-944.

14. Saraç, B.A. and T. Bali, "An Experimental Study on Heat Transfer and Pressure Drop Characteristics of Decaying Swirl Flow through a Circular Pipe with a 
Vortex Generator", Experimental Thermal and Fluid Science 32 (2007) 158-165.

15. Mostafa, A.A., "Effect of Swirl Angle and Geometry on Heat Transfer in Turbulent Pipe Flow", M.Sc. Thesis, Faculty of Engineering, Cairo University (1980).

16. Mostafa, G.M., "Effect of Swirling Angle and Swirler Number on Heat Transfer and Pressure Drop in Turbulent Tube Flow", M.Sc. Thesis, Faculty of Engineering, Cairo University (1987).

17. Durmus, A., İ. Kurtbaş, F. Gülçimen and E. Turgut, "Investigation of the Effect of Co Axis Free Rotating Propeller Type Turbulators on the Performance of Heat Exchanger", Int. Commun. Heat and Mass Transfer 31 (2004) 133-142.

18. Kurtbaş, İ., A. Durmuş, H. Eren and E. Turgut, "Effect of Propeller Type Swirl Generators on the Entropy Generation and Efficiency of Heat Exchangers", Int. J. Thermal Science 46 (2007) 300-307.

19. Eiamsa-ard, S., S. Rattanawong and P.T. Promvonge, "Turbulent Convection in Round Tube Equipped with
Propeller Type Swirl Generators", Int. Commun. Heat and Mass Transfer 36 (2009) 357-364.

20. Vanierschot, M. and E. Van den Bulck, "The Influence of Swirl on the Reattachment Length in an Abrupt Axisymmetric Expansion", Int. J. of Heat and Fluid Flow 29 (2008) 75-82.

21. Dellenback, P.A., D.E. Metzger and G.P. Neitzel, "Heat Transfer to Turbulent Swirling Flow through a Sudden Axisymmetric Expansion", J. of Heat Transfer Vol. 109 (1987) 613-620.

22. Dellenback, P.A., D.E. Metzger and G.P. Neitzel, "Measurement in Turbulent Swirling Flow through an Abrupt Axisymmetric Expansion", American Institute of Aeronautics and Astronautics, 26 (6), (1988), 669-681.

23. Holman, J.P., "Experimental Method for Engineers", $4^{\text {th }}$ Editions, McGraw-Hill Book Company, (1984), New York.

24. Mostafa, A.A. "Effect of Swirl Angle and Geometry on Heat Transfer in Turbulent Pipe Flow" M.Sc. Thesis, Faculty of Engineering Cairo University (1980). 